\title{
Distance Education Course about Sexuality for Obstetrics and Gynecology Residents
}

\section{Curso de educação a distância sobre sexualidade para residentes em Obstetrícia e Ginecologia}

\author{
Teresa Cristina Souza Barroso Vieira ${ }^{1}$ Mary Uchiyama Nakamura ${ }^{1}$ Ivaldo da Silva ${ }^{2}$ \\ Maria Regina Torloni ${ }^{3}$ Meireluci Costa Ribeiro ${ }^{1} \quad$ Eduardo de Souza $^{1}$ \\ ${ }^{1}$ Departament of Obstetrics, São Paulo Medical School, Universidade \\ Federal de São Paulo, São Paulo, Brazil \\ 2 Departament of Gynecology, São Paulo Medical School, \\ Universidade Federal de São Paulo, São Paulo, Brazil \\ ${ }^{3}$ Departament of Internal Medicine, São Paulo Medical School,

\begin{abstract}
Address for correspondence Teresa Cristina S. B. Vieira, MD, PhD, Departamento de Obstetrícia, Escola Paulista de Medicina, Universidade Federal de São Paulo (EPM/Unifesp), Rua Napoleão de Barros, 875, Vila Clementino, CEP 04124-120, São Paulo (SP), Brasil (e-mail: vieira.barroso@unifesp.br).
\end{abstract} Universidade Federal de São Paulo, São Paulo, Brazil

Rev Bras Ginecol Obstet 2017;39:670-675.

\begin{abstract}
Purpose To describe the experience of a distance education course on sexual issues during pregnancy and after birth for residents.

Methods This prospective educational intervention study was conducted by investigators from the Universidade Federal de São Paulo, Brazil, between April and September 2014. The participants were 219 physicians (residents from the 1 st to the 6 th years). The duration of the course was of 24 hours ( 10 video lectures and online chats). At baseline, the participants answered questions about their training, attitude and experience regarding sexual issues during pregnancy and after birth; before and after the course, they answered questions to assess their knowledge about the topic; at the end of the course, they answered questions on the quality of the course. The Student $t$-test was used to compare the before and after scores of the knowledge tests; values of $p<0.05$ were considered statistically significant.

Results A total of 143 residents concluded the course; most were in their 1st (27.2\%) or 3 rd $(29.4 \%)$ years of residency. There was a significant increase in the mean scores of

\section{Keywords}

- pregnancy

- sexology

- medical education

- resident training

- distance education

- obstetrics the questionnaires that assessed the knowledge of the topic: $4.4( \pm 1.6)$ versus 6.0 ( \pm 1.3 ; maximum score: 10$)$, before and after the course respectively $(p<0.0001)$. Most of the participants (74.1\%) declared that the quality of the course as a whole reached their expectations, and $81.1 \%$ would recommend the course to a friend.

Conclusions The online Sexology course for Obstetrics and Gynecology residents increased their knowledge about the sexual issues during pregnancy and after birth, and fulfilled the participants' expectations. The experience described here may serve as a model for other sexuality courses targeting similar audiences.
\end{abstract}

received

July 18,2016

accepted

June 28, 2017

published online

November 27, 2017
Copyright $\odot 2017$ by Thieme Revinter

Publicações Ltda, Rio de Janeiro, Brazil
License terms

(c) (i) $\ominus$ (\$) 10.1055/s-0037-1606273. ISSN 0100-7203. 


\section{Resumo}

Palavras-chave
- gravidez
- sexologia
- educação médica
- treinamento de
residentes
- educação a distância
- obstetrícia

Objetivos Relatar a experiência de um curso de educação a distância sobre questões sexuais na gestação e puerpério para médicos residentes.

Métodos Estudo prospectivo de intervenção educacional, realizado entre abril e setembro de 2014, por investigadores da Universidade Federal de São Paulo. Os participantes foram 219 médicos (R1 a R6). O curso teve carga horária de 24 horas (10 videoaulas e discussões online). No início do curso, os participantes responderam perguntas sobre treinamento, atitude e prática relativas a questões sexuais na gestação; antes e após o curso, responderam perguntas de conhecimento sobre o tema; ao final, preencheram questionário sobre a qualidade do curso. $O$ teste $t$ de Student foi utilizado para comparar os testes de conhecimento, antes e após o curso; valores de $p<0,05$ foram considerados estatisticamente significantes.

Resultados Um total de 143 residentes concluiu o curso; a maioria estava no $1^{\circ}$ $(27,2 \%)$ ou $3^{\circ}(29,4 \%)$ anos de residência. Houve aumento significativo nas notas médias dos questionários que avaliavam o conhecimento sobre o tema: $4,4( \pm 1,6)$ versus 6,0 ( $\pm 1,3$; nota máxima: 10$)$, no início e final do curso, respectivamente $(p<0,0001)$. A maioria dos participantes $(74,1 \%)$ declarou que a qualidade geral do curso atingiu suas expectativas, e $81,1 \%$ recomendariam o curso a um amigo.

Conclusões O curso de Sexologia online para residentes de Ginecologia e Obstetrícia promoveu o aumento do conhecimento sobre questões sexuais no ciclo gravídico puerperal, e atendeu às expectativas dos participantes. Essa experiência pode servir de modelo para outros cursos de sexualidade voltados para esse público.

\section{Introduction}

Sexual health is defined by the World Health Organization (WHO) as "a state of complete physical, mental and social well-being,"1 and one of the goals proposed by the Pan American Health Organization (PAHO) and by the World Association for Sexology (WAS) to promote sexual health is to provide education, training and support to professionals working in sexual health-related fields. ${ }^{2}$

Dealing with human sexuality requires specific knowledge about the different periods of life. ${ }^{3}$ Pregnancy is a unique moment in the lives of men and women, a period when sexual dysfunction symptoms are very frequent and may affect the couple's marital relationship and their quality of life in terms of sexual health. ${ }^{4-7}$

Obstetrics and Gynecology (Ob/Gyn) residents and specialists frequently report that they lack specific knowledge about sexuality, and that they feel unprepared to deal with the sexual issues of their obstetrics patients. ${ }^{8-11}$ On the other hand, pregnant women report they would like to receive more information about sexuality during pregnancy from their healthcare providers during their antenatal care visits. ${ }^{4,12-14}$

A national survey concluded that medical residents are interested in learning more about sexuality during pregnancy to increase their confidence in managing their patients, and that they would appreciate online modules about the topic, due to their lack of time to attend other types of courses. ${ }^{8}$ There are few publications on programs of sexual medicine for medical undergraduates or those specifically focused on medical residents, with some on-site course models. ${ }^{15-18}$ To the best of our knowledge, there are no previous publications of online course models on sexuality during pregnancy.

We developed an online course about sexuality during pregnancy and the postpartum period specifically focused on $\mathrm{Ob} / \mathrm{Gyn}$ residents, to complement their professional training in this area. The main objective of this study was to describe the experience of this distance training course for $\mathrm{Ob} / \mathrm{Gyn}$ residents. We hypothesized that this course would increase the knowledge of the participants about sexuality during pregnancy.

\section{Methods}

\section{Study Design}

This prospective educational intervention study was conducted at the Universidade Federal de São Paulo - São Paulo Medical School (UNIFESP-EPM) in the city of São Paulo, Brazil, from April to September 2014.

\section{Participants}

Medical doctors enrolled in officially accredited Ob/Gyn residency programs in São Paulo were eligible to participate.

\section{Educational Intervention}

Development of the Online Sexology Course Content The course content was based on the recommendations of the Brazilian Federation of Obstetrics and Gynecology (Febrasgo, in the Portuguese acronym) about "What should be the content for a sexology course for Ob/Gyns?". The suggested 
content was adapted and divided into 10 classes. Each class consisted of two 50-minute modules, with a different lecturer for each module. The ten specific topics were: anatomy and physiology of the human sexual response; sexual dysfunctions, paraphilia and sexual inadequacies; the main psychotherapy techniques used in sexology; pharmacotherapy in sexology; the treatment of desire dysfunctions; the treatment of orgasm dysfunctions; the treatment of dyspareunia psychopathology and vaginism; the impact of male sexual dysfunctions on female sexuality; the impact of gynecological surgeries on female sexuality; and ethics in caring for sexual dysfunctions and inadequacies.

We contacted the professionals working in the Sexuality Unit of the Department of Gynecology of Universidade Federal de São Paulo - São Paulo Medical School (UNIFESP-EPM), and invited them to give lectures on the specific topics of the course program. The content of the 10 lectures was divided as follows: 1) Course presentation and content - importance of human sexuality for the Ob/Gyn specialist; 2) History of sexuality/ Anatomy of the sexual response cycle - anatomic changes in pregnancy and after childbirth (pregnancy and childbirth, PC); 3) Physiology of the sexual response - sexual response during pregnancy; 4) Treatment of sexual disorders - treatment of sexual disorders in $\mathrm{PC}$ /sexual history taking; 5) Female sexual dysfunctions (FSDs)- FSD symptoms in pregnancy; 6) Male sexual dysfunctions and pregnant woman's sexuality; 7) Psychotherapy - psychotherapy in PC; 8) Pharmacotherapy pharmacotherapy in PC; 9) Gynecological surgeries and female sexuality - gynecological surgeries and female sexuality in PC; 10) Ethical issues/Treatment of FSDs - sexual education groups with pregnant couples.

In addition to the topics described before, we created three hypothetical clinical cases for discussion during the last video lecture. In all modules, the participants answered four multiple-choice questions related to the topics/clinical cases presented. These questions were created by the lecturers.

At the end of the course, we expected that the participants would be able to: 1 ) have basic knowledge about the anatomy and physiology of the human sexual response; 2) make a diagnosis and propose a treatment for sexual dysfunctions and inadequacies; 3 ) identify particularities of the female sexuality during pregnancy and the postpartum period; 4) understand the impact of male and female sexual dysfunctions on the couple's quality of life in terms of sexual health; 5) care for couples with sexual problems during pregnancy in an ethical and adequate manner; 6) work with a multi-professional team when caring for patients with sexual symptoms during pregnancy and the postpartum period; and 7) appreciate the usefulness of online courses as educational tools.

The course project was submitted to the Medical Residency Committees of all hospitals that participated in this study. We also asked these committees to help us disseminate information about the course to their local Ob/Gyn residents.

\section{Development of the Course Platform, Video Lectures and Assessment Tools}

We hired a professional company experienced in the creation and maintenance of interactive websites to develop one that was specific for our course. The website allowed the participants to register, give informed consent, watch video lectures, participate in chats and have access to four online questionnaires. These questionnaires were created by the investigators to assess: 1) the participants' sociodemographic characteristics; 2) their previous training, attitude and experience about sexuality in pregnancy and the postpartum period; 3 ) their general knowledge about the topic at baseline and after the completion of the course; and 4) their general evaluation of course.

The professional website company also directed and edited the taping of the video lectures that took place between November 2013 and January 2014, in a conference room at our university. The videos were uploaded to a private YouTube channel. The group of lecturers was composed of teachers or professionals working at UNIFESP/EPMour university in the field of human sexuality, and it included Ob/Gyns, urologists, psychiatrists, physiotherapists, psychologists and social workers. Each video lasted 50 minutes, and the lecturers were coached about video communication skills, such as looking directly at the camera, avoiding excessive gesticulation, keeping good body posture and speaking to the participants as individuals.

Two teachers from our Obstetrics Department, who had more than thirty years of experience in the area and were not directly involved with the course, were invited to evaluate the content, language and esthetic quality of the taped lectures using a tool developed for distance education courses by Schons. ${ }^{19}$ The two teachers also evaluated the relevance of the multiple-choice questions created by the lecturers to be answered by the students after watching the videos, to assess the knowledge they had acquired. Both teachers considered all 10 lectures and all suggested questions adequate.

\section{Course Dissemination and Recruitment of Participants} We sent information about the online sexology course to the coordinators of five $\mathrm{Ob} / \mathrm{Gyn}$ residency programs through emails and phone calls, asking them to help us recruit interested participants from their programs. We asked them to explain and emphasize that the course was specifically for Ob/Gyn residents, and that it was free and online.

Throughout March 2014, the principal investigator (TCSBV) personally visited the five residency programs and talked to the residents about the course, encouraging them to enroll. On March 1st, 2014, the website of the course became active, and online registrations were opened. The first page of the website had information about the objectives and contents of the course, the basic curriculum of each lecturer (with links to their full curricula at the Lattes database), how to register and how to give online informed consent.

\section{The Course}

After online registration, the participants received an email confirming their successful enrollment, and were asked to create an individual login and password that ensured the complete confidentiality of their names and personal information. After this step, the participants received three online questionnaires. The first one (the sociodemographic questionnaire) collected 
data about their year of residency, sex and to which residency program they belonged. The second one was based on a questionnaire used in the Evaluate Project, which was conducted by Abdo et $\mathrm{al}^{20}$ and consisted of eight multiple choice questions about the participants' training, attitude and experience regarding sexual issues during pregnancy and the postpartum period. The third questionnaire was a pre-course test that evaluated the participants' baseline knowledge about sexuality in pregnancy and the postpartum period. This questionnaire consisted of 36 multiple choice questions based on the questions created by each of the lecturers. The total score for this test was calculated by dividing the number of questions (36) by 10 , and the result was multiplied by the number of correct questions. The total score of this test ranged from 0 to 10 , with higher scores indicating higher knowledge.

In order to have access to the video lectures, the participants had to fill out the three questionnaires. The first lecture became available on April 7th, 2014, and each subsequent lecture was uploaded weekly, every Monday, along with an invitation to participate in a related discussion at the online forum. The principal investigator was available throughout the course to answer online questions posted by the students in the chat forum. Each participant received a weekly email to remind him/her about the next lecture, along with an invitation to participate in the forum.

The weekly forum offered a list of additional reading material that could be commented by all. The students were encouraged to send questions, comments and suggestions about the video lectures. The principal investigator monitored the forum daily, and answered all questions posted by the students.

After the first lecture, in order to have access to the next one, the student had to answer the four multiple choice questions about the topic of the lecture he/she had watched before. Even if the student did not provide the correct answers to these four questions, he/she was allowed to proceed to the next lecture.

The last lecture was uploaded on June 6th, 2014. One week later, only 11 residents had completed the course. The principal investigator decided to invite these residents to become tutors and help motivate other residents from their own institutions to complete the course. These residents from each participating institution helped other local residents who might be having difficulties in completing the course. The tutors informed the principal investigator about these contacts with their peers. We maintained this strategy until the end of the course, on September 30th, 2014.

At the end of the course, the students were asked to complete another two questionnaires. The "Post-course Test" evaluated their knowledge about sexuality, and consisted of the same 36 questions of the baseline questionnaire, but in a different order. The second questionnaire assessed their satisfaction with the course. This questionnaire was based on the SERVQUAL tool ${ }^{21}$ adapted for educational services. ${ }^{22}$ We modified some of the questions of this multi-item scale to assess video education, and produced a questionnaire with 20 questions divided into 5 domains: tangibles (physical facilities, equipment, personnel and communication materi- als); reliability (performance of the promised service in a reliable and accurate manner); responsiveness (helping students and providing prompt services); assurance (staff knowledge and courtesy, and their ability to convey trust and confidence); and empathy (caring, individualized attention to participants). We added one last question about the general quality of the course. The possible answers ranged from 1 to 5 , with higher scores indicating higher level of satisfaction. The overall internal consistency of the questionnaire and of each domain was assessed using the Cronbach alpha $(\alpha)$ coefficient. The overall consistency of the questionnaire was high $(\alpha=0.9)$, as well as the consistency of each domain (tangibles: $\alpha=0.7$; reliability: $\alpha=0.9$; responsiveness: $\alpha=0.7$; assurance: $\alpha=0.9$; and empathy: $\alpha=0.8$ ).

At the end of the study, each student received an email thanking him/her for his/her participation, along with a certificate of completion and his/her individual scores in the pre and post-tests, along with the list of correct answers to these tests. The residency coordinators also received an email thanking them for their help, a certificate from UNIFESP-EPM and the course assessment of their own residents.

\section{Statistical Aspects}

The Student $t$ and chi-squared tests were used to analyze the results of the pre- and post-course test scores. Descriptive statistics were used for the participants' sociodemographic and professional characteristics. We used Cronbach $\alpha$ to evaluate the internal consistency of the course satisfaction questionnaire. A minimum of Cronbach $\alpha$ of 0.7 had to be present to indicate good internal consistency.

We used the InStat 3 (Statistical Services Centre, University of Reading, Reading, UK) software for the statistical analyses; values of $p<0.05$ were considered statistically significant.

\section{Ethical Aspects}

The study followed the Brazilian National Health Council resolution number 466/12 on research involving humans. The Ethics Committee of Universidade Federal de São Paulo approved the study project (process 05889712.0.0000.5505). All participating residents gave online informed consent when registering for the course.

\section{Results}

A total of 219 residents enrolled in the course, and 143 (65.3\%) completed all activities. The mean age of the participants was $28( \pm 2.1)$ years. Most of them $(188,85.8 \%)$ were female, and $162(74.0 \%)$ were in the first 3 years of residency (R1, R2 and R3). The mean age of the 143 participants who completed the course was 27.9 ( \pm 2.1 ) years; 125 (87.4\%) of them were female, and $116(81.1 \%)$ were in the first 3 years of their residency.

The participants' sociodemographic data and their baseline knowledge about sexuality were presented in a previous publication. ${ }^{9}$ Briefly, most of the residents reported that they did not have any sexology classes during their medical graduation $(62.5 \%)$ or medical residency $(52.1 \%)$, and the majority $(84 \%)$ stated that they lacked specific knowledge about sexuality to help them manage their patients. 
Table 1 Evaluation of 143 obstetrics and gynecology residents about the quality ${ }^{21}$ of an online sexuality course

\begin{tabular}{|l|l|}
\hline Domain & Score \\
\hline Tangibles & $3.7 \pm 0.7$ \\
\hline Reliability & $3.8 \pm 0.7$ \\
\hline Responsiveness & $4.0 \pm 0.6$ \\
\hline Assurance & $3.9 \pm 0.7$ \\
\hline Empathy & $3.9 \pm 0.6$ \\
\hline
\end{tabular}

Note: All values express mean and standard deviation. The total scores range from 1 to 5 , with higher scores indicating higher quality. The evaluation was based on the SERVQUAL questionnaire. ${ }^{21}$

The mean sexuality knowledge scores of the 143 residents who completed the course increased significantly from 4.4 $( \pm 1.6)$ at baseline to $6.0( \pm 1.3)$ at the end of the course (maximum grade: 10$)$, $(p<0.0001)$. Most of the participants $(74.1 \%, 106 / 143)$ reported that the course met their expectations, and $81.1 \%(116 / 143)$ of them would recommend the course to a friend ( - Table $\mathbf{1}$ ).

\section{Discussion}

According to the findings from this study, the online course about sexuality for $\mathrm{Ob} / \mathrm{Gyn}$ residents was effective in increasing the participants' specific knowledge about the topic, and the course was assessed by the residents as good. The high level of participant satisfaction could be due to the multidisciplinary team of lecturers, since this has previously been reported by residents in other educational training activities. ${ }^{16}$

The main reason pointed by the $219 \mathrm{Ob} / \mathrm{Gyn}$ residents to enroll in the course was their perceived need to complement their medical education on sexuality, as pointed by $2 / 3$ of the participants. This was also reported by a previous study by our team, ${ }^{10}$ which involved 154 residents of different specialties (Ob/Gyn, psychiatry and internal medicine) at UNIFESP-EPM. In that study, almost all residents (97\%) declared that they would like to participate in educational activities to increase their knowledge in this area. ${ }^{10}$ These findings suggest that Brazilian residents are acutely aware of their lack of formal training about sexuality during their medical education and residency programs. However, this is not exclusive to Brazil, and has also been reported by international studies. ${ }^{8,17,23}$

The significant increase in test scores indicates that this distance course contributed to increase the participants' knowledge about sexuality. Similar results were reported by Yolsal et al ${ }^{16}$ in a 3-day on-site 20-hour course involving 163 Turkish medical residents of different specialties. The authors also reported significant differences in the mean total scores of knowledge about sexuality before and after the course. They also reported that the residents felt more prepared, motivated and confident to manage sexual issues after the course.

Specific knowledge about sexuality is important for obstetricians and gynecologists to make them feel more capable and confident when handling questions on this topic with pregnant couples, thus potentially optimizing the care given to their patients during this period of their lives. According to previous studies, bringing up, asking, informing and providing counseling about sexuality during pregnancy can increase the couple's quality of life in terms of sexual health. $^{24,25}$

The limited capacity of Ob/Gyn residents to deal with their patients' sexual symptoms and their confidence in online education is also common in other countries. American researchers conducted an online survey involving 234 thirdand fourth-year medical residents to assess their knowledge and confidence regarding female sexual function and dysfunction. The majority of the respondents felt inadequately trained, and reported that they believed that their confidence in caring for patients with sexual problems would increase with lectures (97.9\%) and online modules (90.6\%). ${ }^{8}$

Online distance courses offer several benefits, such as the possibility of learning according to each individual's personal rhythm and time availability, the comfort of being able to watch the video lectures as many times as one wishes, and the time and money saved, since the participant does not have to travel to another location to participate in educational activities. ${ }^{26}$

This study had several strong points. Firstly, it is the largest Latin American study to investigate the training, attitude and experience of $\mathrm{Ob} / \mathrm{Gyn}$ residents about sexuality during pregnancy. It is also the first publication about an online sexuality course. However, this study had several limitations. First, we had to create an unplanned "motivational strategy", with the recruitment of 11 tutors to help increase the number of participants that concluded the course. It is possible that this change in our protocol may have influenced the results of the knowledge acquisition and course satisfaction scores, but we cannot infer the extent of this effect. A second limitation of this study is that, due to its exclusively theoretical nature, this type of course could not address all the practical difficulties that health care professionals face when dealing with sexual problems reported by patients. This would demand a more personalized coaching and practical face to face training with the students. Additionally, we did not assess the post-course knowledge retention and the actual usefulness of the course in improving the participants' skills and confidence in dealing with sexuality with their patients months after the course.

This successful experience can serve as a model to other investigators interested in promoting similar educational interventions on sexuality for medical residents in Brazil and elsewhere. This kind of initiative could help future obstetricians, gynecologists and other professionals improve the care provided to pregnant couples.

More research is needed to confirm the findings of the present study about the effectiveness of online educational interventions to increase the knowledge of young physicians about sexuality.

Conflicts of Interest

Authors declare no conflicts of interest. 


\section{Acknowledgments}

We would like to thank all those who collaborated with ideas, suggestions and support for this study, especially Marco Scanavino, Roseli Nomura, Jorge Hosomi, Renato Santana, Luiz Kulay, Anamaria Facina, Marina Padovani and Eliana Spinelli. We would also like to thank the precious collaboration of the lecturers Alessandra Diehl, Carolina Ambrogini, Denise Queiroz Ferreira, Fátima Ferreira Bortoletti, Gil Facina, Jales Clemente, Marcelo Rodrigues Cabrini, Maria Cláudia de Oliveira Lordello, Miriam Zanetti, Roney Cesar Signorini Filho and Tânia das Graças Mauadie Santana. Finally, we would like to thank Marcus Vinicius Castro for his assistance with the statistical analyses.

\section{References}

1 World Health Organization [Internet]. Sexual health: concept and scope. In: WHO. Developing sexual health programmes: a framework for action. Geneva: WHO; 2010 [cited 2017 Jun 24]. p. 3-6. Available from: http://apps.who.int/iris/bitstream/10665/70501/ 1/WHO_RHR_HRP_10.22_eng.pdf

2 Pan American Health Organization. World Health Organization. World Association for Sexology [Internet]. Promotion of sexual health: recommendations for action. Proceedings of a Regional Consultation; 2000 May 19-22; Antigua Guatemala, Guatemala. Washington (DC): Pan American Health Organization; 2000 [cited 2017 Jun 24]. Available from: http://www1.paho.org/hq/dmdocuments/2008/PromotionSexualHealth.pdf

3 Basson R. The female sexual response: a different model. J Sex Marital Ther 2000;26(01):51-65

4 Pauleta JR, Pereira NM, Graça LM. Sexuality during pregnancy. J Sex Med 2010;7(1 Pt 1):136-142

5 Johnson CE. Sexual health during pregnancy and the postpartum. J Sex Med 2011;8(05):1267-1284, quiz 1285-1286

6 Ribeiro MC, Nakamura MU, Torloni MR, Scanavino MdeT, Scomparini FB, Mattar R. Female sexual function of overweight women with gestational diabetes mellitus - a cross-sectional study. PLoS One 2014;9(04):e95094

7 Babazadeh R, Najmabadi KM, Masomi Z. Changes in sexual desire and activity during pregnancy among women in Shahroud, Iran. Int J Gynaecol Obstet 2013;120(01):82-84

8 Pancholy AB, Goldenhar L, Fellner AN, Crisp C, Kleeman S, Pauls R. Resident education and training in female sexuality: results of a national survey. J Sex Med 2011;8(02):361-366

9 Vieira TC, de Souza E, da Silva I, Torloni MR, Ribeiro MC, Nakamura MU. Dealing with female sexuality: training, attitude, and practice of obstetrics and gynecology residents from a developing country. J Sex Med 2015;12(05):1154-1157
10 Vieira TC, de Souza E, Abdo CH, et al. Brazilian residents' attitude and practice toward sexual health issues in pregnant patients. J Sex Med 2012;9(10):2516-2524

11 Dyer K, das Nair R. Why don't healthcare professionals talk about sex? A systematic review of recent qualitative studies conducted in the United kingdom. J Sex Med 2013;10(11):2658-2670

12 Fok WY, Chan LY, Yuen PM. Sexual behavior and activity in Chinese pregnant women. Acta Obstet Gynecol Scand 2005;84(10):934-938

13 Shojaa M, Jouybari L, Sanagoo A. The sexual activity during pregnancy among a group of Iranian women. Arch Gynecol Obstet 2009;279(03):353-356

14 Trutnovsky G, Haas J, Lang U, Petru E. Women's perception of sexuality during pregnancy and after birth. Aust $\mathrm{N} Z \mathrm{~J}$ Obstet Gynaecol 2006;46(04):282-287

15 Rosen R, Kountz D, Post-Zwicker T, Leiblum S, Wiegel M. Sexual communication skills in residency training: the Robert Wood Johnson model. J Sex Med 2006;3(01):37-46

16 Yolsal N, Karabey S, Bulut A, et al. Courses for medical residents and trainers in Turkey for promotion of quality of reproductive health services: a pilot study. Reprod Health Matters 2004;12(24):189-199

17 Parish SJ, Clayton AH. Sexual medicine education: review and commentary. J Sex Med 2007;4(02):259-267, quiz 268

18 de Medeiros RD, de Azevedo GD, Maranhão TM, et al. [Impact of sexual and reproductive health theme insertion in the undergraduate medical]. Rev Bras Ginecol Obstet 2014;36(03):107-112

19 Schons C. [Validation of criteria for asynchronous didactic material in distance education] [dissertation]. Florianópolis: Universidade Federal de Santa Catarina; 2009. Portuguese

20 Abdo CH, Moreira ED, Santos Junior DB, Wroclawski E, Fitipaldi JAS. Perceptions and attitudes about erectile dysfunction among physicians in Brazil: results from Avaliar Project. Rev Bras Med 2004;61(09):613-619

21 Parasuraman A, Zeithaml VA, Berry LL. SERVQUAL: a multipleitem scale for measuring consumer perceptions of service quality. J Retailing 2002;64(01):12-40

22 Tureta C, Rosa AR, Silva e Oliveira VC. Critical evaluation of educational services: the use of SERVQUAL model. Rev Gest 2007;14(04):33-45

23 Waineo E, Arfken CL, Morreale MK. Sexual health education: a psychiatric resident's perspective. Acad Psychiatry 2010;34(05): 357-360

24 Ribeiro MC, Nakamura MU, Torloni MR, et al. Treatments of female sexual dysfunction symptoms during pregnancy: a systematic review of the literature. Sex Med Rev 2014;2(01):1-9

25 Afshar M, Mohammad-Alizadeh-Charandabi S, Merghti-Khoei ES, Yavarikia P. The effect of sex education on the sexual function of women in the first half of pregnancy: a randomized controlled trial. J Caring Sci 2012;1(04):173-181

26 Tolentino RSS, Gonçalves Filho C, Tolentino RJV, Monteiro PRR. Quality assessment in distance education under the student's perspective: proposing and testing of a model using structural equation. Rev Gest 2013;20(03):347-366 